\title{
Impacts of Financial Development on Energy Consumption Structure: New Evidence from Panel Threshold Regression Model
}

\author{
Shurong Shi ${ }^{1,2^{*}}$, Jingjing Deng ${ }^{3}$ \\ ${ }^{1}$ College of Finance and Statistics, Hunan University, Changsha 410079, China \\ ${ }^{2}$ School of Finance, Hunan University of Finance and Economics, Changsha 410205, China \\ ${ }^{3}$ School of Business, Hunan International Economics University, Changsha 410025, China
}

Corresponding Author Email: ssr@hnu.edu.cn

https://doi.org/10.18280/ijsdp.150312

Received: 17 October 2019

Accepted: 7 January 2020

Keywords:
financial development,
consumption structure (ECS),
threshold regression (PTR)
threshold effect

threshold effect

\begin{abstract}
This paper mainly tests the presence of threshold effect of financial development on energy consumption structure (ECS) with respect to the level of economic development. Based on the panel data of Chinese provinces from 1998 to 2017, the panel threshold regression (PTR) model was adopted to estimate the nonlinear relationship between financial development and the ECS. Two proxies in the scale and efficiency dimensions were designed, and the per-capita GDP was taken as the threshold variable. The results show that the impacts of financial development on the ECS have double threshold features; the correlation between financial development and the ECS changes from negative to positive, with the growing level of economic development. It was also found that economic development, R\&D investment and foreign direct investment all contribute greatly to the ECS optimization, while urbanization and industrial development significantly suppresses the ECS quality. The research results provide reference to the optimization of the ECS through financial means.
\end{abstract}

\section{INTRODUCTION}

Energy consumption, especially the consumption of fossil energy, is the main source of greenhouse gases (GHGs). With the degradation of global environment, governments around the world are striving to build a greener energy consumption structure (ECS), i.e. increase the proportion of clean energy in the ECS. The ECS optimization is a critical way for developing countries to realize sustainable development [1]. China, as the largest developing country and world's leading energy consumer, faces urgent task of optimizing the ECS.

Many scholars have probed into the factors of energy consumption, namely, trade, urbanization, technical innovation, economic growth, and financial development [27]. However, there is little report on the factors of the ECS. The previous studies have shown that financial development, an important driver of economic growth, has a significant impact on energy demand [8-10]. It is possible that financial development may affect the ECS. But the relationship between financial development and the ECS is not yet clear. Thus, this paper examines the impacts of financial development on the ECS based on provincial data of China.

The ECS can be defined as the consumption of a type of energy as a proportion to total energy consumption [11-13]. The resource endowment of China determines that the ECS in the country is dominated by non-clean energies like coal and oil, which emit a huge amount of air pollutants. Thus, the ECS optimization has great environmental significance. To measure the ECS improvement, this paper takes the consumption of clean energies (e.g. natural gas, solar power and nuclear power) as a proportion to total energy consumption as an indicator of the ECS.
Despite the lack of research into the relationship between financial development and the ECS, much attention has been paid to the correlation between financial development and various types of energy. For example, Brunnschweiler [14] proved that financial development has a positive effect on renewable energy consumption in developing countries. Focusing on aggregate energy, Sadorsky [15] discovered that financial development contributes to energy consumption in emerging economics. Many countries have been found to shift from fossil fuels to renewable energies, creating a greener ECS, with the growth in per-capita gross domestic product (GDP) [16]. Best [17] pointed out that, in high-income countries, financial development facilitates the transition from fossil fuels to renewable energies, especially wind; in low-income countries, financial development supports the change from biomass to fossil fuels like coal.

Unlike previous studies, this paper discusses the relationship between financial development and the ECS. The nonlinear effect of financial development on the ECS was investigated with panel threshold regression (PTR) model. This approach helps to identify endogenously different economy regimes defined by the level of economic development, and gauge the varied impacts of financial development on the ECS across the different identified regimes. To the best of our knowledge, our research marks the first attempt to implement a nonlinear panel framework in this context.

The remainder of the paper is organized as follows: Section 2 introduces the theoretical bases and puts forward research hypotheses; Section 3 explains the methodology and data sources; Section 4 analyzes the empirical results; Section 5 draws the conclusions and presents several countermeasures. 


\section{THEORETICAL BASES AND HYPOTHESES}

Financial development could affect the ECS through two channels, namely, economic growth and technical innovation. The ECS adjustment is the result of a mutual game between the consumption of non-clean energies (i.e. fossil fuels like coal and oil), and that of clean energies (i.e. non-fossil fuels and natural gas). The two impact channels vary with the levels of economic development.

The impact via economic growth is called the scale effect. With the growing economy, financial development pushes up energy production and consumption, boosting the consumption of non-clean and clean energies at the same time. However, the scale effect changes with the levels of economic development, causing changes to the ECS. Komal and Abbas [18] argued that, if the economic development is on low levels, economic growth depends on industrial development. It is known that all that industrial development needs to consume a huge amount of coal and oil for many years. During this period, the non-clean energy consumption is promoted far more evidently than clean energy consumption by the scale effect of financial development. Therefore, the ECS may undergo limited changes at a low level of economic development. If the economic development is on high levels, Mittlefehldt [19] held that the government will release many favorable policies for clean energy industry, due to the increase of income and growing desire for a better life. In this case, the region becomes less dependent on coal and oil, with the economic development. As a result, financial development exerts a greater impact on clean energy consumption than on coal and oil. Therefore, the ECS may change to the better direction at a high level of economic development.

The impact via technical innovation is known as the substitution effect. The innovation of energy technologies is the key to addressing climate change and catalyzing the global transformation of the ECS. Dogan and Seker [20] believed that technical innovation requires a large amount of long-term capital investment, which is available in a prosperous financial market. Technical innovation improves production efficiency, while reducing the consumption of non-clean energy. Mundaca et al. [21] demonstrated that technical innovation can solve technical difficulties in clean energy production. Hsu et al. [22] noticed that, whichever the level of economic development, financial development always has a positive impact on the ECS via technical innovation, but the impact magnitude varies with the levels of economic development. Under a good environment of technical innovation, the economy will grow and the infrastructure will be improved. Then, the same investment on technical innovation will yield more results. Hence, the substitution effect is more prominent at higher levels of economic development.

With the changing levels of economic development, the magnitude and direction could vary for both scale and substitution effects. If the economic development is on low levels, the government tends to over-emphasize economic growth. Then, the financial capital mostly flows to industries of traditional energies (e.g. coal and oil). In this case, the scale effect is greater than substitution effect. Once the economic development reaches high levels, the industry structure is optimized, and the environmental awareness increases. Thus, the clean energy industry will start to attract more financial capital. In this case, the scale effect is smaller than the substitution effect.

Through the above analysis, the following hypotheses were put forward:

H1: There exists a threshold effect in the relationship between financial development and the ECS with respect to the level of economic development.

H2: Financial development has a negative impact on the ECS at low levels of economic development, and a positive impact on the latter at high levels of economic development.

\section{METHODOLOGY AND DATA SOURCES}

\subsection{Methodology}

To begin with, it is assumed that financial development is linearly correlated with the ECS. Then, various panel regressions were conducted to derive the baseline results. The basic econometric benchmark model can be expressed as:

$$
e s_{i t}=\alpha_{0}+\beta f d_{i t}+\lambda^{\prime} x_{i t}+\mu_{i}+\varepsilon_{i t}
$$

where, $i$ is the region; $t$ is the time; es is the ECS; $f d$ is the proxy variables of financial development; $x$ is a set of control variables; $\mu_{i}$ is the fixed effects of region $i$; $\varepsilon_{i t}$ is the error term; $\alpha_{0}$ is the intercept.

Inspired by Hansen [23], a PTR model was established to disclose how the impact of financial development on the ECS varies with levels of economic development. The singlethreshold model can be defined as:

$$
\begin{aligned}
& e s_{i t}=\beta_{1} f d_{i t} I\left(q_{i t} \leq \gamma\right)+\beta_{2} f d_{i t} I\left(q_{i t}>\gamma\right) \\
& +\lambda^{\prime} x_{i t}+\mu_{i}+\varepsilon_{i t}
\end{aligned}
$$

where, $I(\bullet)$ is the indicator function; $q_{i t}$ is the threshold variable (the level of economic development) that divides the observations into two regimes; $\beta_{1}$ and $\beta_{2}$ are two different regression slopes; $x_{i t}$ is the vector of exogenous regressors. For simplicity, $x_{i t}$ is assumed to have the same impact in both regimes. The individual-specific effects are eliminated through standard fixed-effects transformation implying for the identification of $\beta_{1}$ and $\beta_{2}$.

For a given threshold $\gamma$, the slope coefficients $\beta_{1}$ and $\beta_{2}$ can be estimated by ordinary least squares (OLS) using the data after the fixed-effects transformation. To estimate the value of $\gamma$, it is necessary to search over a subset of the threshold variable $q_{i t}$. The estimator of $\gamma$ is the value that minimizes the residual sum of squares (RSS):

$$
\hat{\gamma}=\underset{\gamma}{\arg \min } S_{1}(\gamma)
$$

where, $S_{l}(\gamma)$ is the RSS obtained through the estimation by formula (2) for threshold $\gamma$. Moreover, unbiased estimates of $\beta_{1}$ and $\beta_{2}$, which are crucial for the significance test of a threshold, can be described by the following linear constraint:

$H_{0}: \beta_{I}=\beta_{2}$.

If there are multiple thresholds, i.e. multiple regimes, the model should be fitted sequentially. The double-threshold model can be defined as:

$$
\begin{aligned}
& E S_{i t}=\beta_{1} F D_{i t} I\left(q_{i t} \leq \gamma_{1}\right)+\beta_{2} F D_{i t} I\left(\gamma_{1}<q_{i t} \leq \gamma_{2}\right) \\
& +\beta_{3} F D_{i t} I\left(q_{i t}>\gamma_{2}\right)+\lambda^{\prime} X_{i t}+\mu_{i}+\varepsilon_{i t}
\end{aligned}
$$


where, $\gamma_{1}$ and $\gamma_{2}$ are the thresholds that divide the equation into three regimes with coefficients $\beta_{1}, \beta_{2}$, and $\beta_{3}$. The thresholds can be estimated as follows:

Step 1. Fit the single-threshold model to obtain the threshold estimator $\gamma_{1}$ and the RSS $S_{1}\left(\hat{\gamma}_{1}\right)$.

Step 2. Based on the obtained $\hat{\gamma}_{1}$ value, the second threshold can be obtained by:

$$
\begin{aligned}
& \hat{\gamma}_{2}=\arg \min S_{2}\left(\gamma_{2}\right), \\
& S_{2}=S\left\{\min \left(\hat{\gamma}_{1}, \gamma_{2}\right) \max \left(\hat{\gamma}_{1}, \gamma_{2}\right)\right\} .
\end{aligned}
$$

Step 3. Since $\hat{\gamma}_{2}$ is efficient but $\hat{\gamma}_{1}$ is not, the first threshold can be re-estimated by:

$$
\begin{aligned}
& \hat{\gamma}_{1}=\underset{\gamma_{1}}{\arg \min } S_{1}\left(\gamma_{1}\right), \\
& S_{1}\left(\gamma_{1}\right)=S\left\{\min \left(\gamma_{1}, \hat{\gamma}_{2}\right) \max \left(\gamma_{1}, \mid \hat{\gamma}_{2}\right)\right\} .
\end{aligned}
$$

The threshold-effect test is sequential, that is, if the null hypothesis is rejected in a single-threshold model, then it must be tested by the double-threshold model.

The process is similar for models with more than two threshold parameters. Chan [24] proved that dependence of the estimation and inference of $\beta$ on the threshold estimate is not of first-order asymptotic importance. Thus, the inference of $\beta$ can be proceed because the $\gamma$ value is given.

\subsection{Data sources}

The research dataset is a balanced panel of the annual ECS and financial development of 30 provincial administrative regions (hereinafter referred to as provinces) in China over 20 years from 1998 to 2017.

The ECS was measured by the clean energy consumption as a proportion to total energy consumption (es). The term clean energy refers to the energy sources that bring low pollution (e.g. natural gas and nuclear energy) or no pollution (e.g. solar power, wind, biomass, terrestrial heat and other renewable energies). These consumption data were extracted from the China Energy Statistical Yearbooks.

Drawing on relevant literature, two proxies from two dimensions were adopted to measure financial development. In the scale dimension, the size of financial sector was described by the assets of deposit money banks (DMBs) as a proportion of GDP (scale) [15, 25]; in the efficiency dimension, the quality of financial services was depicted by the private domestic credit issued by the DMBs as a proportion of GDP (efficiency) [26, 27], because this proxy focuses on credit issued to the private sector. These financial data were obtained from the China Statistical Yearbooks and the Almanac of China's Finance and Banking.

The following control variables were employed to isolate the effects from other influencing factors on the ECS:

(1) Industry structure (industry): added value of secondary industry as a proportion of regional GDP;

(2) Foreign direct investment $(f d i)$ : the actual amount of foreign direct investment as a proportion of regional GDP;

(3) R\&D investment $(r d)$ : internal expenditure on $R \& D$ investment as a proportion of regional GDP;

(4) Urbanization (urban): urban population as a proportion of total population;

(5) Level of economic development (ed): per-capita GDP (this control variable is also the indicator of the threshold variable).

The data on the control variables were mostly collected from the China Statistical Yearbooks, and the data on R\&D investment were partly obtained from the China Statistical Yearbooks of Science and Technology.

The descriptive statistics of our data are listed in Table 1 below.

Table 1. Descriptive statistics of various variables

\begin{tabular}{ccccccc}
\hline Variables & Unit & Sample size & Mean & Standard deviation & Minimum & Maximum \\
\hline es & $\%$ & 600 & 16.571 & 14.212 & 0.061 & 62.024 \\
scale & $\%$ & 600 & 1.112 & 0.381 & 0.553 & 4.172 \\
efficiency & $\%$ & 600 & 0.654 & 0.294 & 0.091 & 2.736 \\
industry & $\%$ & 600 & 38.521 & 8.083 & 11.926 & 53.154 \\
fdi & $\%$ & 600 & 0.327 & 0.415 & 0.032 & 3.135 \\
rd & $\%$ & 600 & 0.286 & 0.514 & 0.072 & 3.055 \\
urban & $\%$ & 600 & 46.735 & 16.935 & 0.934 & 89.658 \\
ed & yuan per capita & 600 & $26,974.464$ & $22,750.537$ & $2,364.032$ & $118,198.300$ \\
\hline
\end{tabular}

\section{RESULTS ANALYSIS}

\subsection{Baseline results}

The results of fixed-effects and random-effects models were compared to identify the relationship between financial development and the ECS under linear assumption. The original data were corrected by natural logarithms to eliminate potential heteroscedasticity and dimensional difference between series. The corrected data are listed in Table 1. The Hausman specification test was conducted to decide between fixed-effects and random-effects estimates, under the full set of random-effects assumptions. The test results invalidated the random-effects assumptions. Therefore, the fixed-effects estimates were adopted for subsequent analysis.

It is learned that the two proxies of financial development (i.e. scale and efficiency) have opposite effects on the ECS.
The coefficient of scale is significantly positive at the $5 \%$ level, while the coefficient of efficiency is negative. These results challenge the linear assumption, and reflect the following situation: In recent years, the asset scale of financial institutions is continuously expanding in every province, but the quality of financial services is not satisfactory; private firms have difficulty in financing, especially in underdeveloped provinces. Thus, a nonlinear panel framework was implemented to analyze the effect of financial development on the ECS.

As for control variables, the estimated coefficients of $\ln e d$, $r d$ and $f d i$ are significantly positive at the 5\% level, reflecting that economic development, $\mathrm{R} \& \mathrm{D}$ investment and foreign direct investment contribute greatly to the ECS optimization. By contrast, the estimated coefficients of urban and industry are negative; the coefficient of industry is significantly negative at the $5 \%$ level. This is attributable to the long-term 
dominance of coal in the ECS, as determined by China's resource endowment; the rapid urbanization and industrial growth are at the expense of resource depletion and environmental damages.

Table 2. The baseline results

\begin{tabular}{|c|c|c|c|c|}
\hline & \multicolumn{2}{|c|}{ Financial development: scale dimension } & \multicolumn{2}{|c|}{ Financial development: efficiency dimension } \\
\hline & Fixed-effects estimates & Random-effects estimates & Fixed-effects estimates & Random-effects estimates \\
\hline \multirow[t]{2}{*}{$f d$} & $0.794 * *$ & $0.831^{* * *}$ & -0.034 & -0.028 \\
\hline & $(0.316)$ & $(0.320)$ & $(0.258)$ & $(0.203)$ \\
\hline \multirow[t]{2}{*}{$\ln e d$} & $0.074 * *$ & $0.127 * * *$ & $0.213 * * *$ & $0.272 * * *$ \\
\hline & $(0.033)$ & $(0.049)$ & $(0.061)$ & $(0.064)$ \\
\hline \multirow[t]{2}{*}{ urban } & -0.025 & -0.035 & -0.015 & -0.024 \\
\hline & $(0.749)$ & $(0.657)$ & $(0.851)$ & $(0.764)$ \\
\hline \multirow[t]{2}{*}{$r d$} & $0.338 * *$ & $0.327 * *$ & $0.327 * * *$ & $0.318 * *$ \\
\hline & $(0.133)$ & $(0.128)$ & $(0.112)$ & $(0.132)$ \\
\hline \multirow[t]{2}{*}{ industry } & $-0.706 * * *$ & $-0.740 * * *$ & $-1.240 * * *$ & $-1.272 * * *$ \\
\hline & $(0.203)$ & $(0.242)$ & $(0.313)$ & $(0.353)$ \\
\hline \multirow[t]{2}{*}{$f d i$} & $0.215^{* * *}$ & $0.164 * * *$ & $0.203 * * *$ & $0.154 * * *$ \\
\hline & $(0.052)$ & $(0.061)$ & $(0.063)$ & $(0.057)$ \\
\hline \multirow{2}{*}{ _cons } & $1.839^{*}$ & $1.752 *$ & $2.580 * *$ & $2.458 * *$ \\
\hline & (1.075) & $(0.986)$ & $(1.015)$ & (1.017) \\
\hline Hausman test & \multirow{2}{*}{\multicolumn{2}{|c|}{$\begin{array}{c}31.961 * * * \\
{[0.000]}\end{array}$}} & \multirow{2}{*}{\multicolumn{2}{|c|}{$\begin{array}{c}27.746 * * * \\
{[0.003]}\end{array}$}} \\
\hline p_value & & & & \\
\hline$R^{2}$ & 0.645 & 0.578 & 0.664 & 0.503 \\
\hline$N$ & 600 & 600 & 600 & 600 \\
\hline
\end{tabular}

Note: The numbers in parentheses and square brackets are standard errors and p-values, respectively; *,** and $* * *$ refer to the significance levels of $10 \%, 5 \%$ and $1 \%$, respectively.

Table 3. The threshold effects between financial development and the ECS

\begin{tabular}{cccccc}
\hline Financial development variables & Threshold effect & $\mathbf{F}$ & p-value & Threshold value & 95\% confidence interval \\
\hline \multirow{2}{*}{ scale } & Single & $40.198^{* * *}$ & 0.006 & 9.513 & {$[9.380,9.971]$} \\
& Double & $28.017^{* * *}$ & 0.032 & 11.069 & {$[10.736,11.347]$} \\
& Triple & 7.651 & 0.106 & 11.351 & {$[11.014,11.423]$} \\
\hline \multirow{2}{*}{ efficiency } & Single & $77.667^{* * *}$ & 0.000 & 9.196 & {$[9.163,9.373]$} \\
& Double & $18.574^{* *}$ & 0.048 & 11.230 & {$[9.367,11.349]$} \\
& Triple & 4.346 & 0.170 & 11.364 & {$[10.612,11.524]$} \\
\hline Note & &
\end{tabular}

Note: F-statistics and p-values were obtained by repeating the bootstrap procedures 500 times for each of the three bootstrap tests; *, ** and $* * *$ refer to the significance levels of $10 \%, 5 \%$ and $1 \%$, respectively.

\subsection{Results of the PTR model}

Table 4. The estimated coefficients of each variable with double-threshold model

\begin{tabular}{ccc}
\hline & $\begin{array}{c}\text { Financial } \\
\text { development: } \\
\text { scale dimension }\end{array}$ & $\begin{array}{c}\text { Financial } \\
\text { development: } \\
\text { efficiency dimension }\end{array}$ \\
\hline$f d\left(\ln e d \leq \hat{\gamma}_{1}\right)$ & $-0.388^{* *}$ & $-0.880^{* * *}$ \\
$f d\left(\hat{\gamma}_{1}<\ln e d \leq\right.$ & $(0.195)$ & $(0.254)$ \\
$\left.\hat{\gamma}_{2}\right)$ & 0.207 & 0.211 \\
$f d$ (lned $\left.>\hat{\gamma}_{2}\right)$ & $(0.216)$ & $(0.247)$ \\
ed & $1.431^{* * *}$ & $2.150^{* * *}$ \\
& $(0.428)$ & $(0.451)$ \\
urban & $0.127^{* * *}$ & $0.200^{* * *}$ \\
& $(0.046)$ & $(0.058)$ \\
$r d$ & 0.080 & 0.019 \\
& $(0.691)$ & $(0.797)$ \\
industry & $0.308^{* *}$ & $0.304 * *$ \\
& $(0.129)$ & $(0.127)$ \\
$f d i$ & $-0.377^{* * *}$ & $-0.338^{* *}$ \\
& $(0.115)$ & $(0.161)$ \\
cons & $0.193^{* * *}$ & $0.241^{* * *}$ \\
& $(0.068)$ & $(0.067)$ \\
$N$ & $1.151^{* * *}$ & $1.864^{* * *}$ \\
& $(0.579)$ & $(0.685)$ \\
\hline
\end{tabular}

Note: The numbers in parentheses are standard errors; $*, * *$ and $* * *$ refer to the significance levels of $10 \%, 5 \%$ and $1 \%$, respectively.
During the PTR, the first step is to test whether there is a threshold. If the null hypothesis is rejected, then the threshold effect does exist. Here, a bootstrap method is applied to approximate the F-statistics and then calculate the p-values.

Table 3 above presents the empirical results of the singlethreshold, double-threshold and triple-threshold tests. After repeating the bootstrap procedures 500 times for the PTR tests, the p-values of the two proxies of financial development (i.e. scale and efficiency) are significant with the single-threshold model and double-threshold model at the 5\% level. However, the test with triple-threshold model is statistically insignificant. This confirms that our data can be sufficiently described with a double-threshold model.

According to the estimated thresholds $\left(\hat{\gamma}_{1}, \hat{\gamma}_{2}\right)=(9.513$, 11.069) for scale and those $\left(\hat{\gamma}_{1}, \hat{\gamma}_{2}\right)=(9.196,11.230)$ for efficiency, the levels of economic development, as measured by the natural logarithm of per-capita GDP (logPCGDP), were divided into three regimes: a low regime $\left(\log P C G D P<\hat{\gamma}_{1}\right)$, a medium regime $\left(\hat{\gamma}_{1} \leq \log \mathrm{PCGDP} \leq \hat{\gamma}_{2}\right)$, and a high regime $\left(\log P C G D P>\hat{\gamma}_{2}\right)$

Table 4 displays the results of double-threshold model on the impacts of each variable on the ECS. In the scale dimension, the coefficient of financial development was negative when the logPCGDP was less than 9.513, and is statistically significant at the 5\% level. When the logPCGDP surpassed the first threshold of 9.513, the coefficient of financial development turned to be positive. The higher the 
per-capita GDP, the greater the positive impact of financial development on the ECS. When the logPCGDP was greater than 11.069, the coefficient of financial development was 1.431 , and is statistically significant at the $1 \%$ level.

In the efficiency dimension, the impact of financial development on the ECS is similar to that in the scale dimension. This impact is significantly negative, when the $\log$ PCGDP was below the first threshold of 9.916. The impact became positive from the low to the medium/high regime. These results prove that the impact of financial development on the ECS cannot be sufficiently described by the linear regression model, but with a nonlinear panel framework. The sign and significance of control variables are similar to those in the former subsection.

\subsection{Mechanism analysis}

As mentioned before, financial development could affect the ECS through scale and substitution effects. The overall impact is the combination between the two effects. To further clarify the impact mechanism of financial development on the ECS, this subsection explores the two effects by static panel data model with interaction terms.

Based on the threshold value, the samples were divided into two groups: the low-level economic development group $\left(q_{i t} \leq\right.$ $\hat{\gamma}_{1}$ ) (low-level group) and the high-level economic development group $\left(q_{i t}>\hat{\gamma}_{2}\right)$ (high-level group).

According to Wooldridge (2015), the interaction term mitigates the multicollinearity effect by removing mean correction. The maximum value of the variance inflation factor (VIF) was 8.17 , which is lower than 10 . This means the multicollinearity effect has been eliminated.

Tables 5 and 6 provide the estimation results with scale and efficiency as proxies, respectively. The results in Table 5 were analyzed as follows: The estimation results of the model without interaction terms (column 1) are consistent with the results in Table 4. This means financial development has a statistically significant, negative impact on the ECS at lowlevels of economic development, and a statistically significant, positive impact on the ECS at high-levels of economic development. The results also confirm that the impacts of financial development on the ECS have threshold features for different levels of economic development.

The estimation results of the model with interaction terms are reported in column 2. At low-levels of economic development, the coefficient of $f d \times \ln e d$ was -0.855 , and is statistically significant at the $5 \%$ level; meanwhile, the coefficient of $f d \times r d$ is 0.024 , and is statistically significant at the $5 \%$ level. Hence, the negative impact of financial development on the ECS increased from 0.102 to 0.339 , indicating that the financial development exerts a significant negative impact on the ECS via the scale effect, but a significant positive impact via the substitution effect. At highlevels of economic development, the coefficient of $f d \times \ln e d$ was 0.015 , and is statistically significant at the $10 \%$ significance level; meanwhile, the coefficient of $f d \times r d$ was 0.301 , and is statistically significant at the $5 \%$ significance level. Thus, the positive effect of financial development on the ECS increased from 0.132 to 0.330 , indicating that the financial development exerts a significant negative impact on the ECS via the substitution effect, but a significant positive impact via the scale effect.

Similar conclusions can be drawn from the estimation results in Table 6.
Table 5. The results for mechanism analysis with scale as the proxy

\begin{tabular}{|c|c|c|c|c|}
\hline & \multicolumn{2}{|c|}{ Low-level group } & \multicolumn{2}{|c|}{ High-level group } \\
\hline & $(1)$ & $(2)$ & (1) & (2) \\
\hline & & $-0.155^{* *}$ & & $0.115^{*}$ \\
\hline jaxinea & & $(0.064)$ & & (0.069) \\
\hline$f d \times r d$ & & $\begin{array}{l}0.064^{* *} \\
(0.027)\end{array}$ & & $\begin{array}{l}0.301^{* *} \\
(2.009)\end{array}$ \\
\hline$f d$ & $\begin{array}{c}-0.102^{* * *} \\
(0.036)\end{array}$ & $\begin{array}{c}-0.339^{* * *} \\
(0.098)\end{array}$ & $\begin{array}{c}0.132^{* * *} \\
(0.041)\end{array}$ & $\begin{array}{c}0.330^{* * *} \\
(0.126)\end{array}$ \\
\hline lned & $\begin{array}{c}-0.209^{* * *} \\
(0.074)\end{array}$ & & $\begin{array}{c}0.371^{* * *} \\
(0.104)\end{array}$ & \\
\hline$r d$ & $\begin{array}{l}0.385^{* * *} \\
(0.066)\end{array}$ & & $\begin{array}{c}0.501^{* * *} \\
(0.098)\end{array}$ & \\
\hline industry & $\begin{array}{c}-0.516^{* * *} \\
(0.063)\end{array}$ & $\begin{array}{l}-0.156^{*} \\
(0.088)\end{array}$ & $\begin{array}{c}-0.358^{* * *} \\
(0.097)\end{array}$ & $\begin{array}{c}-0.513^{* * *} \\
(0.128)\end{array}$ \\
\hline urban & $\begin{array}{c}0.108 \\
(0.086)\end{array}$ & $\begin{array}{c}0.134 \\
(0.094)\end{array}$ & $\begin{array}{l}0.275^{* *} \\
(0.139)\end{array}$ & $\begin{array}{l}0.104^{* *} \\
(0.051)\end{array}$ \\
\hline$f d i$ & $\begin{array}{c}-0.102 \\
(0.066)\end{array}$ & $\begin{array}{l}-0.115 \\
(0.073)\end{array}$ & $\begin{array}{c}0.122^{*} \\
(0.071)\end{array}$ & $\begin{array}{c}0.126^{*} \\
(0.069)\end{array}$ \\
\hline _cons & $\begin{array}{c}-7.806 * * * \\
(1.032)\end{array}$ & $\begin{array}{l}-2.486^{*} \\
(1.321)\end{array}$ & $\begin{array}{l}1.018^{* * *} \\
(0.254)\end{array}$ & $\begin{array}{c}4.344^{* * *} \\
(0.635)\end{array}$ \\
\hline Observations & 180 & 180 & 90 & 90 \\
\hline
\end{tabular}

Note: The numbers in parentheses are standard errors; $*, * *$ and $* * *$ refer to the significance levels of $10 \%, 5 \%$ and $1 \%$, respectively.

Table 6. The results for mechanism analysis with efficiency as the proxy

\begin{tabular}{ccccc}
\hline & \multicolumn{2}{c}{ Low-level group } & \multicolumn{2}{c}{ High-level group } \\
\cline { 2 - 5 } & $(1)$ & $(2)$ & $(1)$ & $(2)$ \\
\hline \multirow{2}{*}{$f d \times \ln e d$} & & $-0.254^{* * *}$ & & 0.105 \\
& & $(0.061)$ & & $(0.063)$ \\
$f d \times r d$ & & $0.244^{* *}$ & & $0.518^{* *}$ \\
& & $(0.107)$ & & $(0.243)$ \\
$f d$ & -0.105 & $-0.119^{* * *}$ & $0.546^{* * *}$ & $0.876^{* * *}$ \\
& $(0.049)$ & $(0041)$ & $(0.172)$ & $(0.226)$ \\
lned & $-0.186^{* * *}$ & & 0.096 & \\
& $(0.061)$ & & $(0.064)$ & \\
$r d$ & $0.228^{* * *}$ & & $0.232^{* * *}$ & \\
& $(0.088)$ & & $(0.061)$ & \\
industry & -0.104 & 0.133 & $-0.266^{* *}$ & $-0.233^{* *}$ \\
& $(0.089)$ & $(0.096)$ & $(0.112)$ & $(0.089)$ \\
urban & 0.201 & 0.162 & $-0.152^{* *}$ & $-0.242^{* *}$ \\
fdi & $(0.129)$ & $(0.114)$ & $(0.071)$ & $(0.119)$ \\
cons & & & & \\
Observations & $\left(0.156^{* * *}\right.$ & $2.152^{* * *}$ & $-3.745^{* * *}$ & $-1.180^{* *}$ \\
The & 150 & $(0.757)$ & $(1.239)$ & $(0.459)$ \\
\hline
\end{tabular}

Note: The numbers in parentheses are standard errors; $* * *$ and $* * *$ refer to the significance levels of $10 \%, 5 \%$ and $1 \%$, respectively.

\section{CONCLUSIONS}

Based on the panel data of Chinese provinces from 1998 to 2017, the PTR model was adopted to estimate the nonlinear relationship between financial development and the ECS. Both scale and efficiency were taken as proxies for financial development, and per-capita GDP as the threshold variable.

The estimation results attest to a double threshold effect in the relationship between financial development and the ECS. When the per-capita GDP is below the first threshold, the coefficient of financial development is negative and statistically significant, which means financial development suppresses the share of clean energy in the energy portfolio. When the per-capita GDP is between the two thresholds, the coefficient of financial development is positive. When the per- 
capita GDP is above the second threshold, the coefficient of financial development is even greater and statistically significant. These results indicate that, in medium and high regimes, financial development can increase the share of clean energy in the energy portfolio, thereby optimizing the ECS.

The results also show that economic development, R\&D investment and foreign direct investment all contribute greatly to the ECS optimization, while urbanization and industrial development significantly suppresses the ECS quality.

Based on these findings, three countermeasures were put forward to promote green finance and the optimization of the ECS:

(1) Attentions should be paid to the nonlinear relationship between financial development and the ECS. The financial development cannot promote the ECS optimization at low levels of economic development. Therefore, it is important to maintain stable and sustained economic development, and to achieve a rapid increase in per-capita GDP.

(2) China should strive to improve the level of financial development. The finance industry in China faces the problem of low efficiency, as evidenced by the financing difficulty of private firms. To encourage technical innovation, private firms, especially high-tech private firms, should receive more financial resources.

(3) More investments should be directed at innovation Commercial banks must provide technology innovation projects with sufficient funds, and support the listing and financing of technology innovation firms. In this way, the financial resources will flow to developers of energy-saving technologies and the industry of clean energy.

\section{ACKNOWLEDGEMENTS}

This work was supported financially by Natural Science Foundation of Hunan Province (2019JJ40041), Hunan Provincial Innovation Foundation for Postgraduate (CX2018B157) and Scientific Research fund of Hunan Provincial Education Department (18B525).

\section{REFERENCES}

[1] Weng, Q., Xu, H., Ji, Y. (2018). Growing a green economy in China. In Proceedings of IOP Conference Series: Earth and Environmental Science, 121: 52-82. https://doi.org/10.1088/1755-1315/121/5/052082

[2] Tuna, G., Tuna, V.E. (2019). The asymmetric causal relationship between renewable and NONRENEWABLE energy consumption and economic growth in the ASEAN-5 countries. Resources Pol, 62: 114-124 https://doi.org/10.1016/j.resourpol.2019.03.010

[3] Ji, Q., Zhang, D. (2019). How much does financial development contribute to renewable energy growth and upgrading of energy structure in China? Energy Policy, 128:

114-124 https://doi.org/10.1016/j.enpol.2018.12.047

[4] Wang, S., Li, G., Fang, C. (2018). Urbanization, economic growth, energy consumption, and $\mathrm{CO} 2$ emissions: Empirical evidence from countries with different income levels. Renewable and Sustainable Energy Reviews, 81(P2): 2144-2159. https://doi.org/10.1016/j.rser.2017.06.025
[5] Pata, U.K. (2018). Renewable energy consumption, urbanization, financial development, income and $\mathrm{CO}_{2}$ emissions in Turkey: Testing EKC hypothesis with structural breaks. Journal of Cleaner Production, 187: 770-779. https://doi.org/10.1016/j.jclepro.2018.03.236

[6] Cetin, M., Ecevit, E., Yucel, A.G. (2018). The impact of economic growth, energy consumption, trade openness, and financial development on carbon emissions: empirical evidence from Turkey. Environmental Science and Pollution Research, 25: 36589-36603. https://xs.scihub.ltd/https://doi.org/10.1007/s11356-0183526-5

[7] Chen, W., Lei, Y. (2018). The impacts of renewable energy and technological innovation on environmentenergy-growth nexus: New evidence from a panel quantile regression. Renewable Energy, 123: 1-14. https://doi.org/10.1016/j.renene.2018.02.026

[8] Ouyang, Y., Li, P. (2018). On the nexus of financial development, economic growth, and energy consumption in China: New perspective from a GMM panel VAR approach. Energy Economics, 71: 238-252. https://doi.org/10.1016/j.eneco.2018.02.015

[9] Furuoka, F. (2015). Financial development and energy consumption: Evidence from a heterogeneous panel of Asian countries. Renewable and Sustainable Energy Reviews, 52: 430-444. https://doi.org/10.1016/j.rser.2015.07.120

[10] Shahbaz, M., Hye, Q.M.A., Tiwari, A.K., Leitão, N.C. (2013). Economic growth, energy consumption, financial development, international trade and $\mathrm{CO}_{2}$ emissions in Indonesia. Renewable and Sustainable Energy Reviews, 25: 109-121. https://doi.org/10.1016/j.rser.2013.04.009

[11] Lin, B., Raza, M.Y. (2019). Analysis of energy related $\mathrm{CO}_{2}$ emissions in Pakistan. Journal of Cleaner Production, 219: 981-993. https://doi.org/10.1016/j.jclepro.2019.02.112

[12] Wang, S., Li, C., Zhou, H. (2019). Impact of China's economic growth and energy consumption structure on atmospheric pollutants: Based on a panel threshold model. Journal of Cleaner Production, 236: 117694. https://doi.org/10.1016/j.jclepro.2019.117694

[13] Bilgen, S. (2014). Structure and environmental impact of global energy consumption. Renewable and Sustainable Energy Reviews, 38: 890-902. https://doi.org/10.1016/j.rser.2014.07.004

[14] Brunnschweiler, C.N. (2010). Finance for renewable energy: an empirical analysis of developing and transition economies. Environment and Development Economics, 15(3): 241-274. https://doi.org/10.2139/ssrn.1462207

[15] Sadorsky, P. (2010). The impact of financial development on energy consumption in emerging economies. Energy Policy, 38(5): 2528-2535. https://doi.org/10.1016/j.enpol.2009.12.048

[16] Burke, P.J. (2013). The national-level energy ladder and its carbon implications. Environment and Development Economics, 18(4): 484-503. https://doi.org/10.1017/S1355770X13000090

[17] Best, R. (2017). Switching towards coal or renewable energy? The effects of financial capital on energy transitions. Energy Economics, 63: 75-83. https://doi.org/10.1016/j.eneco.2017.01.019 
[18] Komal, R., Abbas, F. (2015). Linking financial development, economic growth and energy consumption in Pakistan. Renewable and Sustainable Energy Reviews, 44: 211-220. https://doi.org/10.1016/j.rser.2014.12.015

[19] Mittlefehldt, S. (2018). From appropriate technology to the clean energy economy: Renewable energy and environmental politics since the 1970s. Journal of Environmental Studies and Sciences, 8: 212-219. https://doi.org/10.1007/s13412-018-0471-z

[20] Dogan, E., Seker, F. (2016). The influence of real output, renewable and non-renewable energy, trade and financial development on carbon emissions in the top renewable energy countries. Renewable and Sustainable Energy Reviews, 60 1074-1085 http://dx.doi.org/10.1016/j.rser.2016.02.006

[21] Mundaca, L., Busch, H., Schwer, S. (2018). 'Successful' low-carbon energy transitions at the community level? An energy justice perspective. Applied Energy, 218: 292-303. https://doi.org/10.1016/j.apenergy.2018.02.146

[22] Hsu, P.H., Tian, X., Xu, Y. (2014). Financial development and innovation: Cross-country evidence.
Journal of Financial Economics, 112(1): 116-135. https://doi.org/10.1016/j.jfineco.2013.12.002

[23] Hansen, B.E. (1999). Threshold effects in non-dynamic panels: Estimation, testing, and inference. J. Econometrics, $\quad$ 93(2): 345-368. https://doi.org/10.1016/S0304-4076(99)00025-1

[24] Chan, K.S. (1993). Consistency and limiting distribution of the least squares estimator of a threshold autoregressive model. The Annals of Statistics, 21(1): 520-533. https://doi.org/10.1214/aos/1176349040

[25] Creane, S., Goyal, R., Mubarak, A.M., Sab, R. (2006). Measuring financial development in the Middle East and North Africa: A new database. IMF Staff Papers, 53(3): 479-511. https://doi.org/10.2307/30035923

[26] Beck, T., Levine, R. (2004). Stock markets, banks, and growth: Panel evidence. Journal of Banking \& Finance, 28(3): 423-442. https://doi.org/10.1016/S03784266(02)00408-9

[27] Cole, R.A., Moshirian, F., Wu, Q. (2008). Bank stock returns and economic growth. Journal of Banking \& Finance, 32(6): 995-1007. 